\title{
A QUESTÃO DO ARGUMENTO SOCIAL-ONTOLÓGICO NA FILOSOFIA SOCIAL: A INSTITUIÇÃO SOCIAL COMO FONTE DE PESQUISA CRÍTICO-NORMATIVA
}

\author{
José Henrique Sousa Assai ${ }^{1}$ \\ Pontifícia Universidade Católica do Rio Grande do Sul (PUCRS) \\ Universidade Federal do Maranhão (UFMA) \\ (D) https://orcid.org/0000-0002-5846-4997
}

\section{RESUMO:}

A filosofia social se ocupa fundamentalmente de três tarefas: pelo conceito sobre uma instituição, como ela funciona e como ela se efetiva. Nesse sentido, um desafio que se apresenta para a filosofia social, sob o ponto de vista da pesquisa crítico-normativa, é pensar a instituição social não só como espinha-dorsal da sociedade, mas, sobretudo, em pensar sua possibilidade vinculativa ao argumento social-ontológico com orientação à emancipação; ou seja, de que maneira a instituição social ocupa sua tarefa crítica em promover os bens sociais e direitos sociais na urdidura social. Pretendo nessa pesquisa explicitar a exigência filosófica-social do argumento social-ontológico na tratativa da pesquisa crítico-normativa tomando em consideração que, primeiramente, a instituição social se autocompreende enquanto medium à emancipação e, em segundo, que a referida instituição provém de uma concepção destranscendental da razão o que remete como corolário de pesquisa a uma forma de pensar a filosofia social inserida desde a sua gênese constitutiva nos contextos históricos das comunidades sociais.

PALAVRAS-CHAVE: Teoria crítica; Ontologia social; Instituição social.

\section{THE ISSUE OF SOCIAL-ONTOLOGICAL ARGUMENT AT SOCIAL PHILOSOPHY: THE SOCIAL INSTITUTION AS SOURCE OF RE- SEARCH CRITICAL-NORMATIVE}

\begin{abstract}
:
Social philosophy takes care of three tasks: the conceptual idea about an institution, how it functions and how it accomplish. In this sense, a challenge to social philosophy, from the point of view of critical-normative research, is to think of the social institution not only as the backbone of society, but, above all, to link it with the social-ontological argument with emancipatory approach; in other words, how a social institution how to deal with its task of promoting social goods and social rights. I intend to explain the philosophical-social requirement of the social-ontological argument in the discussion of critical-normative research taking into account that, at first, the social institution is understand itself as a medium to emancipation and, secondly, this institution stem from a detranscendental reason conception and this refer to a new way to think the social philosophy inside in the historical background of ours social communities.
\end{abstract}

KEYWORDS: Critical theory; Social ontology; Social institution.

\footnotetext{
${ }^{1}$ Doutorando em Filosofia pela Pontifícia Universidade Católica do Rio Grande do Sul (PUCRS), Rio Grande do Sul - Brasil. Estágio doutoral sanduíche com o apoio da CAPES/PDSE na Europa Universität Flensburg Institut für Soziologie/ European Studies (Alemanha) sob a orientação do prof. Dr. Hauke Brunkhorst. Professor de Filosofia da Universidade Federal do Maranhão (UFMA), Maranhão-Brasil. E-mail: jhsassai@ufma.br
}

ASSAI, José Henrique Sousa. A questão do argumento social-ontológico na filosofia social: a instituição social como fonte de pesquisa crítico-normativa. Griot : Revista de Filosofia, Amargosa, Bahia, v.16, n.2, p.205-220, dezembro/2017. 


\section{Contextualizando a pesquisa: teoria crítica e "Sozialontologisches Argument"}

Certa vez Habermas afirmou a existência de três esferas temáticas que dominam todo o seu empreendimento filosófico, a saber: esfera pública, discurso e razão (HABERMAS, 2007, p. 19). Naquela ocasião pareceu oportuno a Habermas que o mesmo fizesse uma anamnese clínica de sua vida tomando como centro de reflexão a interface "teoria e história de vida". Ao leitor desse relato ficou, no mínimo, a sensação de que o labor acadêmico/pesquisa não deveria ser (estar) dissociado da vida do sujeito que se encontra envolto em suas teias sociais, culturais, históricas, enfim, humanas. E ainda mais: a triádica temática (esfera pública, discurso e razão) encontra-se de tal forma amalgamada entre si a ponto de se estabelecer interfaces entre si mesmas sem exaurir o conteúdo próprio de cada uma e, ao mesmo tempo, vinculando-as a outras temáticas numa forma estruturalmente interdisciplinar (OLIVEIRA, 2016, 271p). Creio que essa metodologia do tipo "Sitz im Leben" não cai numa vacuidade teórica e nem fica reservada aos "mais doutos"; porém, ela é possível de se efetivar numa pesquisa e ainda mais no presente artigo onde procuro estabelecer um vínculo temático entre uma forma de argumento filosófico (sozialontologisches Argument) e uma específica forma de pesquisa (crítica-normativa). $O$ intuito fundamental, portanto, é explicitar que os pressupostos arrolados numa pesquisa críticonormativa não são (estão) dissociados de um argumento ontológico-social cujo fundamento se assenta, por princípio, na tarefa emancipatória de uma instituição social. Não pretendo elaborar nessa pesquisa uma ontologia social de forma teórica, mas empreender uma tratativa argumentativa de maneira que o pressuposto básico de uma ontologia social (a entidade social/ o ente social) seja visto como uma possibilidade normativa de (na) pesquisa crítica (STAHL, 2013, 475p). Para esse intento, quero explicitar primeiramente a questão sobre o argumento social-ontológico na pesquisa crítico-social demarcando o pressuposto racional (a razão destranscendental) como base dessa explicitação (I) cuja variante destranscendental (Habermas) se vincula, em um segundo momento, a uma perspectiva social-ontológica (II) (de telos normativo) (Honneth, Rahel Jaeggi e Titus Stahl). Tal empreendimento nos conduzirá para as práticas institucionais que passam a serem compreendidas enquanto exequibilidade de uma instituição social constituir-se em um medium à emancipação reiterando, assim, a profícua tarefa do pensamento crítico (III).

(I) Em "Kommunikatives Handeln und detranszendentalisierte Vernunft" (HABERMAS, 2001, 87p.) Habermas admite que as práticas cotidianas sejam traduzíveis numa expressão na qual ele cognominou de "razão corporificada"(verkörperten Vernunft) (HABERMAS, 2001,p.8). Esse adjetivo atribuído à razão nem de longe é inocente e nem verborrágico; porém, ao contrário, expressa radicalmente uma forma de se "situar a razão" no contexto de uma pesquisa filosófica possibilitando, por assim dizer, um corolário normativo de pesquisa crítica. A consequência desta "adjetivação" atinge um maior patamar: "a cisão transcendental entre o ideal e o real, o reino do inteligível e o do fenômeno, desloca-se (muda-se) (para a) na realidade social dos nexos de ações e das instituições" (HABERMAS, 2001, p.8). É com essa perspectiva que o tema das instituições emerge nessa pesquisa enquanto possibilidade de mediação normativa no sentido de que as instituições sociais enquanto entes sociais (daí a ideia de ontologia social) podem ser autocompreendidas

ASSAI, José Henrique Sousa. A questão do argumento social-ontológico na filosofia social: a instituição social como fonte de pesquisa crítico-normativa. Griot : Revista de Filosofia, Amargosa, Bahia, v.16, n.2, p.205-220, dezembro/2017. 
enquanto medium à práxis. Nessa minha pesquisa, portanto, assumo a posição de exequibilidade da abordagem social-ontológica na pesquisa crítica - instituição social como medium normativo tomando por referência uma compreensão racional de caráter destranscendental. Nesse sentido, a razão se despe de sua forma mais "sublime" qual seja a transcendental - e toma a forma "profana" de um determinado "soziale Lebenswelt". É com essa orientação que o sujeito social juntamente com a ação (falar e agir) forma o que Habermas chamou de processo de destranscendentalização da razão. Esse tema da razão que se ocupa das contingências históricas de nossas realidades - levando a alcunha de filosofia social - na qual consista em uma cariz normativa não é tão recente no círculo frankfurtiano. Ainda mais em se tratando de uma filosofia social que se ocupa em explicitar e identificar os vestígios de uma ontologia social cuja temática, por princípio, seja a instituição social como potência para a emancipação na qual se oriente, sobretudo, pela efetivação (Verwirklichung) dos bens sociais e dos direitos sociais (sozialen Gütern und Rechten) (JAEGGI, 2009, p.528). Na perspectiva da abordagem ontológica-social para a pesquisa crítica creio que na obra "The Fragmented World of the Social: Essays in Social and Political Philosophy" Honneth atribuiu bons créditos para a filosofia social cuja possibilidade de orientação se estabeleça sob o argumento social-ontológico:

The essential features of modern ontology can be explained without too much effort in terms of the principle of the logic of identity. Castoriadis utilizes mathematical set theory to develop the rules which in their entirety serve as a formal system of reference for that ontology. For him, those operations which are necessary for the formation of a set of clearly distinguished objects simultaneously also represent the cognitive schemata with whose help reality is constructed as a structure of specifiable entities according to the logic of identity. If thereby traditional ontology has its logical foundation in the operations of forming sets, then its practical roots are to be found in the concerns of the reality of social life [...] Using the concepts of ancient philosophy, Castoriadis calls these elementary human performative achievements, without which the reproduction of society would be impossible, legein and teukein. According to his argument, the performance of both activities, discursive speech and technical action, brings about an identifying determination of states of affairs and thereby also a categorial fixation of being. For speech and work to be possible, reality must be specified in clearly determined entities. Therefore the ontology of the modern period which is centered in the logic of identity is to be understood as an unreflected generalization of those modes of thought based on the postulation of identity which are necessarily carried out in everyday action (HONNETH, 1995, 343p)

Penso que nessa passagem quando Honneth, retomando o pensamento socialontológico de Castoriadis, se fixou no princípio de identidade presente na realidade da vida social pareceu-me que ele ensejou uma aproximação com uma forma de pensar a razão enquanto destranscendental, ou seja, ela - a razão - não ocupa apenas um locus no pensamento transcendental, porém, assenta-se em um espaço eivado de determinidade (na linguagem hegeliana). Aí o pensamento identitário se funde com as práticas sociais emergentes do agir humano permitindo, portanto, um olhar filosófico mais acurado não só para as práticas sociais, mas também ao agir (práxis) e ao pensar (ação metafísica) vinculando-os com esse "espaço" destranscendental que se

ASSAI, José Henrique Sousa. A questão do argumento social-ontológico na filosofia social: a instituição social como fonte de pesquisa crítico-normativa. Griot : Revista de Filosofia, Amargosa, Bahia, v.16, n.2, p.205-220, dezembro/2017. 
galvaniza, por assim dizer, na realidade social. O mundo social, portanto, ocupa um lugar heurístico na reflexão filosófica-social no momento no qual, a partir do corolário remissivo da relação 'agir e práxis', passa a ser entendido enquanto uma expressão de uma determinada forma de vida (Lebensform) (JAEGGI, 2014a, 451 p.) oriunda de uma autocompreensão racional destranscendentalizada.

Retomando: a consequência de uma forma de se pensar a razão enquanto destranscendental ensejou sob o ponto de vista da gênese constitutiva do programa da Kritische Theorie mais pormenorizadamente do ponto de vista crítico-normativo o repensar sobre o mundo da vida social (soziale Lebenswelt) e seus contextos multifacetados eivados de situações conflitivas e que exigem respostas com vistas à resolução desses mesmos problemas. Tal posicionamento, a meu ver, pressupôs no Frankfurter Kreis uma perspectiva revisionista do próprio socialismo (HONNETH, 1990, 223p; JAEGGI, 2014b, 274p; JAEGGI, Rahel, LOICK, Daniel, 2014a, 518 p.; JAEGGI, 2013, 307p; HONNETH, 2014, 670p; HONNETH, 2015, 167p.) como base teórica de uma filosofia social. Assim, perante o olhar filosófico a razão corporificada se revela dialeticamente e na práxis como luta pelas conquistas políticas, sociais e econômicas de uma sociedade eivada de patologias (HONNETH, 2007, 239 p). Nesse processo de desacoplamento destranscendental a razão se corporifica, "dessublimase", despe-se de sua aura metafísica-transcendental, assumindo, sob a perspectiva filogênica, formas sociais e organizacionais (BODE, 1997, 366 p.) que, por sua vez, ela mesma na condição de assumir uma modalidade destranscendental inserida na pesquisa crítica e na contingência do caleidoscópio de mundos da vida atinge um patamar normativo de ação. Dessa forma, a razão tanto ao se destranscendentalizar quanto na vinculação com a pesquisa crítica insere-se de maneira filogênica na situação epocal (hic et nunc) de um determinado contexto de vida possibilitando, assim, que o mundo social se eleve a um patamar crítico-reflexivo-normativo de pensamento e ação.

O conceito destranscendental da razão - o alter ego do seu lado transcendental - pode ser vinculado, a meu ver, com uma abordagem social-ontológica - e, nesse caso, mais pormenorizadamente em Honneth -, pois se admitirmos a ideia de que a razão se corporifica (na linguagem honnethiana) ela passa a se constituir também enquanto um potencial "Platzhalter" normativo na urdidura social e essa, por sua vez, assume uma forma tradutível dessa "incorporação da razão" mediante a instituição social como telos emancipador. Apresento, a seguir, o quadro teórico honnethiano como forma de explicitar a importância de uma abordagem social-ontológica na pesquisa filosófica social.

\section{"Sozialontologisches Argument" na pesquisa crítica: o déficit de institucionaliza- ção em "Leiden an Unbestimmtheit"}

Em 2001 Honneth encetou em seu livro "Leiden an Unbestimmtheit" (HONNETH, 2001, 127p.) - ou "Sofrimento de Indeterminação"(SId) na versão brasileira (HONNETH, 2007, 145p.) -, precisamente no primeiro capítulo intitulado " $A$ Filosofia do Direito de Hegel como teoria da justiça", a forma como ele pensa no tocante à releitura da Filosofia do Direito de Hegel:

ASSAI, José Henrique Sousa. A questão do argumento social-ontológico na filosofia social: a instituição social como fonte de pesquisa crítico-normativa. Griot : Revista de Filosofia, Amargosa, Bahia, v.16, n.2, p.205-220, 
[...] um esclarecimento atualizador do pensamento que Hegel exprime com sua formulação dificilmente compreendida de que a "ideia" da "vontade livre universal" determina o âmbito total daquilo que devemos chamar de "direito"; eu tento interpretar essa determinação como o núcleo de uma teoria da justiça que visa à garantia universal das condições intersubjetivas de autorrealização individual [...] (HONNETH, 2001, p. 16).

Honneth parte da ideia de que para repensar a tarefa de uma Teoria Crítica que se dedique às patologias sociais bem como às suas propostas de solução é preciso inserir a eticidade (Sittlichkeit) nessa discussão e não apenas ficar na moralidade no modelo kantiano. Para ele, a eticidade parece dar conta de modo mais satisfatório do problema de uma ordem social mais justa e que não se oriente apenas por critérios dedutivos como queria Kant. Disso, duas questões se apresentam a respeito da moralidade segundo Honneth: a primeira, a afirmação quanto ao propósito da crítica a Kant no caminho da busca por princípios normativos no ordenamento social e, nessa orientação, Honneth expõe quatro pressupostos no qual o primeiro postula o seguinte: "[...] em razão do fato de os sujeitos já se encontrarem constantemente ligados em relações intersubjetivas, tal justificação dos princípios universais de justiça não deve partir da representação atomista segundo a qual a liberdade dos indivíduos residia no exercício tranquilo, e não influenciado pelos outros, do arbítrio universal" (HONNETH, 2007, p.54). A segunda questão repousa no questionamento honnethiano para com a moralidade kantiana como condição de auxílio numa pesquisa social, ou seja, como pensar o binômio 'sociedade e seus problemas', por um lado, e, por outro, resolução de conflitos e mediação social pela via institucional já que

\footnotetext{
é importante separar, na objeção hegeliana à ideia de autonomia moral de Kant, os dois elementos que ele apresenta de um só fôlego: enquanto a censura à cegueira em face do contexto, que põe em questão a possibilidade de uma aplicação livre do imperativo categórico trata de um argumento ligado à teoria moral no sentido estrito, a proposta de entender a realidade social como incorporação da razão apresenta no fundo um argumento epistemológico, ou melhor, ontológico-social (HONNETH, 2007, p. 95)
}

A minha suspeita de que a reconstrução normativa a qual Honneth se propõe exigira que o mesmo tomasse a sério um pensar ontológico social, mas ele não o fez nem em SId e nem nas demais obras que se seguem a essa (HONNETH, 2015, 167 p.; HONNETH, 2014, 670 p.); pois Honneth parece admitir em SId que uma abordagem ontológica-social é fundamental e não contingente para dar conta das patologias sociais e, de forma específica, das questões institucionais sob o ponto de vista de que as instituições possam ser vistas, sob o enfoque da eticidade democrática, como medium para a resolução de conflitos. No tocante à eticidade e à moralidade, a querela entre Kant e Hegel, sob o âmbito da filosofia do Direito, ganha força nesse contexto ainda mais no tocante à gramática dos conflitos morais no qual é o ponto de partida para Honneth. Nesse sentido, o atual diretor do Instituto de Pesquisa Social acolhe o postulado hegeliano contra Kant de que

a questão de saber o que deve então valer como um conflito moral, como um desafio prático, remete indiretamente ao ponto que Hegel provavel-

ASSAI, José Henrique Sousa. A questão do argumento social-ontológico na filosofia social: a instituição social como fonte de pesquisa crítico-normativa. Griot : Revista de Filosofia, Amargosa, Bahia, v.16, n.2, p.205-220, dezembro/2017. 
mente está visando com sua crítica: enquanto abstrairmos o fato de que sempre nos movemos em um ambiente social no qual aspectos e pontos de vista morais já se encontram institucionalizados, a aplicação do imperativo categórico permanecerá ineficaz e vazia; mas se ao contrário aceitarmos a circunstância de que o ambiente social já sempre nos apresenta traços de deliberação moral, então o imperativo categórico perde sua função de fundamentação (HONNETH, 2007, p.95)

O conteúdo assertórico descrito acima se assenta na práxis institucionalizada dos contextos sociais e na preocupação da emancipação aos problemas sociais (na linguagem de Honneth "patologias sociais"). Chamo a atenção ao termo "institucional" no qual é amiúde apresentado por Honneth no contexto de "Sofrimento de Indeterminação" (SId). Já na introdução na versão brasileira feita por Denilson Werle e Rúrion Melo o termo institucionalização aparece, tomando por referência apenas na terceira parte, doze vezes. Para além de uma tênue exegese o que me traz a reflexão é a insistência do conceito - ou ideia - da institucionalização bem como mais ainda o seu pressuposto mais filosófico: a liberdade que enquanto ideia se efetiva na sociedade por meio da vontade livre. Para Honneth, é aí que ocorre o sofrimento de indeterminação quando justamente há insuficiente manifestação da liberdade efetivando-se na história e, particularmente, na autodeterminação da subjetividade. Por isso, a eticidade - como que formando a tríade hegeliana juntamente com o direito abstrato e com a moralidade - é capaz, segundo Hegel e Honneth, de dar respostas mais "atrativas" às patologias sociais. A intuição honnethiana não ficou apenas em "SId" (HONNETH, 2007, p. 18 - 56) para tratar da "institutionelle Einbettung" (incorporação/inserção institucional) como pressuposto básico para se pensar uma crítica da sociedade (Gesellschaftskritik).

A questão a respeito da "institutionelle Einbettung" faz emergir a crítica de Honneth à Kant já que a "cegueira em face do contexto [...] a aplicação do imperativo categórico, a ação permanece sem orientação e "vazia", uma vez que o sujeito não recorre a algumas prerrogativas normativas das práticas institucionalizadas de seu mundo circundante" (HONNETH, 2007, p.94), porém creio que em "Leiden an Unbestimmtheit", Honneth deixa escapar um pensar normativo sobre as instituições, pois ao recepcionar a teoria hegeliana do direito foi-lhe oportuno tratar da esfera social no fito de "entender a realidade social como incorporação da razão [...] um argumento ontológico-social" (sozialontologisches Argument) (HONNETH, 2003, p.66; HONNETH, 2007, p.95; LUBENOW, 2013, p. 157-190) ${ }^{2}$. Parece-me que nessa passagem Honneth nos permite pensar que uma teoria da sociedade ou mais precisamente um pensar filosófico social sobre as instituições sociais pode ser mediado pela argumentação ontológica-social; porém, em algumas passagens em "SId" perce-

\footnotetext{
${ }^{2}$ A crítica de Honneth à Kant volta para o próprio Honneth quando o mesmo não trata em "SId" sobre "como" fazer para que os agentes sociais participem da práxis emancipatória ("patologias sociais) para que se efetive a liberdade pelos canais institucionais. É verdade que em "SId" Honneth não se propõe a isso, mas minha questão neste artigo é evidenciar a necessidade de que Honneth - tomando o projeto hegeliano da liberdade que se efetiva no ordenamento social - precisa "lançar mão" de uma ontologia social, tal como ele mesmo afirmou em seu livro. Se ele fica apenas numa descrição analítica das patologias sociais torna-se complicada tal argumentação. Nesse sentido, é que a mesma crítica de um déficit institucional-normativo endereçada ao Habermas cabe também ao Honneth, claro que em contextos distintos.
}

ASSAI, José Henrique Sousa. A questão do argumento social-ontológico na filosofia social: a instituição social como fonte de pesquisa crítico-normativa. Griot : Revista de Filosofia, Amargosa, Bahia, v.16, n.2, p.205-220, dezembro/2017. 
be-se esse déficit do "como" e "o que" pensar normativamente sobre as instituições e não apenas em "dizer" que é preciso tê-las enquanto mediadoras para coordenação de ações (e ainda mais ações de caráter normativo). Reitero que a minha crítica à Honneth se fundamenta na exigência explicitativa acerca do "conteúdo" com os quais essas instituições possam se efetivar no propósito da autoefetividade (ou autorrealização) enquanto mediadoras de ação que visam à práxis tomando em conta um arranjo normativo de democracia (democracia deliberativa) (FORST, 1996, p.194 238).

A argumentação na qual Honneth parte para chegar à ideia de eticidade e que dá ancoragem ao seu pensamento filosófico social em "SId" ocorre da seguinte forma: da gramática moral temos as expectativas não satisfeitas que geram desrespeito (moral) e o que motiva a luta social (reconhecimento) no qual há exigência de uma concepção formal de eticidade (vida boa). Na esfera da eticidade com o telos à práxis, segundo Honneth, parece que a razão deve ser compreendida incorporada ao contexto social no qual "desde jâ" "temos de partir aqui de um conceito de racionalidade que já se manifestou em nossas mentalidades e tradições, em nossas normas e valores" (HONNETH, 2007, p.96). Honneth admite, portanto, que esses quatro aspectos (HONNETH, 2001, p.68) (Mentalitäten, Überlieferungen, Normen, Werten) da racionalidade "incorporada" (Verkörperung von Vernunft) são fundamentais para o entendimento no tocante às patologias sociais. Não obstante, reside a questão de como conciliar tais pressupostos com os processos institucionalizados (família, corporações/sociedade civil e Estado) para a efetivação da liberdade mediante a expressão da vontade livre. Nessa tentativa "conciliadora" e sob o ponto de vista da Filosofia do Direito hegeliana, Honneth reforça a ideia da realidade social como tarefa filosófica ao afirmar que

Hegel está interessado no que deve ser incorporado nessa realidade social, na "existência", para que com isso a "vontade livre" individual possa se desenvolver e se realizar, ainda que não diretamente em uma instituição do direito caracterizada juridicamente; já insistimos que as relações comunicativas, que possibilitam ao sujeito individual em "ser-consigo-mesmono-outro", devem pertencer essencialmente às condições de tal realização (HONNETH, 2001, p.31; HONNETH, 2007, p.62).

O termo alemão utilizado no texto para 'existência" é "dasein", isto é, uma existência como sendo a base social e institucional para a efetivação da vontade livre. Isso significa que só há uma existência real se a mesma estiver circunscrita no âmbito da imediaticidade e determinidade social. Honneth parece que nessa passagem não só reitera o postulado hegeliano da realidade social, mas também retoma a filosofia habermasiana da ação comunicativa no que diz respeito ao Direito enquanto medium normativo das (nas) relações sociais. Essas relações comunicativas pressupostas nas "formas da existência social" (sozialen Daseinsformen) exigem, no meu entendimento, uma base mínima de "conteúdo" social, ou seja, quais são (ou seriam) essas condições não só formais, porém empíricas e/ou procedimentais (na linguagem habermasiana) que as instituições necessitam(riam) ter para efetivar essa vontade livre? Nessa passagem bem como em outras no texto na versão alemã me parece mais adequado traduzir o termo "Verwirklichung" por "efetivação/efetividade" por se tratar de

ASSAI, José Henrique Sousa. A questão do argumento social-ontológico na filosofia social: a instituição social como fonte de pesquisa crítico-normativa. Griot : Revista de Filosofia, Amargosa, Bahia, v.16, n.2, p.205-220, dezembro/2017. 
uma releitura da filosofia hegeliana e não "apenas" por "realização" como ocorre em "SId". Inclusive, ainda nessa passagem, a nota de rodapé na versão alemã não me deixa dúvida no tocante a uma tradução mais aproximada ao escopo hegeliano. Daí o termo "efetividade ou efetivação" ter mais sentido do que o termo "realização". Em todo caso, Honneth não se ocupa da questão sobre "quais" condições as instituições deveriam ter para efetivar (o exercício da) a vontade livre. É bem verdade que não foi esse o fito fundamental em "SId", mas, a meu ver, Honneth deixa por "inacabado" o seu projeto de reconstrução normativa e ainda mais explicitamente tanto em "O Direito à Liberdade" (HONNETH, 2014, 411p; PINZANI, 2013, 241p.; SOBOTTKA, 2008, p.9 - 18; LIMA, 2014, 21 p.) quanto em "Luta por Reconhecimento" (HONNETH, 2003, 296 p.) também não está clara essa preocupação de Honneth sob o enfoque de um "sozialontologisches Argument" - no que diz respeito aos conteúdos dessas instituições no sentido normativo (ou os argumentos ontológico-sociais como o próprio Honneth afirma em "SId"). Daí é que, na minha concepção, emerge como contraponto ao "sofrimento de determinação" um "êxito de determinação" que eu cognominei noutro lugar de "Erfolg an Bestimmtheit"(ASSAI, 2015, p. 226 244) já que esse contraponto se estabelece a partir da exigência de se apresentar minimamente as determinações que possam efetivar a vontade livre dessas mesmas formas de existência social inseridas nas práticas de vida institucionalizadas (institutionalisierten Lebenspraxis). Nesse contexto, a determinação ganha um sentido positivo e não restritivo e, ademais, no projeto de fundamentar um caminho possível para esse processo da determinação das "institutionalisierten Lebenspraxis" as instituições sociais passam a ocupar um espaço (Raum der Gründe) como esse medium normativo. Ter o "êxito na determinação" é levar em conta as orientações que suscitem as resoluções das patologias sociais no sentido de que o "determinar" ganhe status não apenas analítico (como faz Honneth), mas normativo (propor, por exemplo, quais são [seriam] esses bens primários (Grundgut) (HONNETH, 2001, p.29) nos quais os processos institucionais devem se orientar minimamente tendo como telos à efetivação da vontade livre). Esse movimento de um "Erfolg an Bestimmtheit" vincula-se a uma forma destranscendental de razão já que à incorporação da razão se acopla também as práticas de vida institucionalizadas. De certa forma, portanto, o projeto filosófico para se pensar a razão enquanto "corporificada" - uma forma da razão ser "sensível" para com as contingências históricas - também já fora visitado pelo próprio Habermas (HABERMAS, 2001, 87p.). Revisitar o conceito de razão “destranscendentalizada" ou de razão corporificada, como propõe tanto Honneth quanto Habermas, deve, sim, servir de paradigma filosófico-social que leve em conta a necessidade de se ter justamente "o argumento ontológico-social" como base de explicitação e pesquisa crítico-normativa na medida em que o referido argumento recepciona o processo de efetivação de uma instituição social com orientação à práxis.

Convém assinalar que o termo "sozialontologisches Argument" (HONNETH, 2001, p.66) só ocorre uma única vez em "Leiden an Unbestimmtheit" e Honneth o utiliza tomando por referência dois aspectos: o primeiro, em relação à caracterização da esfera da eticidade (Sphäre der Sittlichkeit) que se opõe à "cegueira em face do contexto" kantiano (HONNETH, 2007, p.63); já o segundo, para entender a efetividade social enquanto corporificação da razão. Prefiro utilizar o termo "efetividade" (Wirklichkeit) e não realidade, como o faz Rúrion Melo, por Honneth se vincular ao

ASSAI, José Henrique Sousa. A questão do argumento social-ontológico na filosofia social: a instituição social como fonte de pesquisa crítico-normativa. Griot : Revista de Filosofia, Amargosa, Bahia, v.16, n.2, p.205-220, dezembro/2017. 
legado da filosofia hegeliana nesse contexto e, nesse sentido, a ideia de efetividade adquire maior tônus filosófico do que a ideia de realidade. $\mathrm{O}$ termo "Wirklichtkeit" é fulcral nessa passagem, pois o pressuposto social-ontológico em "Leiden an Unbestimmtheit" parece fazer a mediação entre a "Hegels Rechtsphilosophie als Theorie der Gerechtigkeit" e "Die Sittlichkeitslehre als normative Theorie der Moderne" respectivamente primeira e terceira partes da referida obra onde tal mediação apresenta não só a necessidade de Honneth explicitar que na Filosofia do Direito hegeliana o que "está em jogo" é a autorrealização (ou autoefetivação) do sujeito que se orienta para a liberdade, mas também em afirmar que uma forma de se pensar a eticidade no tocante às práticas de vida institucionalizadas é justamente interpor o argumento socialontológico como proposta de pesquisa crítica no quadro de uma filosofia social.

Se retomarmos esse argumento no qual para entendermos uma determinada realidade social como substrato de uma razão incorporada (Verkörperung von Vernunft) encontramos, em última análise, um argumento ontológico-social que se traduz enquanto esfera da eticidade, então - para além da querela entre Hegel e Kant sob o ponto de vista da moralidade e da eticidade - podemos anuir que o argumento honnethiano carece de maior explicitação. No mínimo, penso que Honneth precisaria - o que ele não fez em "SId" - explicitar o que ele pensa sobre os processos institucionais presentes nos mundos da vida diferenciados que visam resolver as patologias sociais nos quais se ancoram em um pressuposto social-ontológico (HONNETH, 2007, p.29). A despeito desse déficit institucional em Honneth existem, contrariamente, outros indícios de um pressuposto ontológico-social no pensamento filosófico social da Tradição Crítica e são com algumas dessas referências (Rahel Jaeggi, Titus Stahl) com as quais explicito a seguir.

\section{Filosofia Social e argumento social-ontológico: instituição social e emancipação}

A questão de um "Sozialontologisches Argument" na pesquisa crítica não está reservada, ainda que seja enquanto elemento de vacuidade filosófica, na filosofia social honnethiana, mas é também tema fundamental de um projeto de filosofia social tal como Rahel Jaeggi empreendeu (JAEGGI, 2009, p.528 - 544).

Para Rahel Jaeggi a tarefa profícua de uma filosofia social, sob o ponto de vista crítico, é tematizar as instituições sociais no tocante ao fracasso das mesmas quanto a não promoção da vida boa cuja autorreferência se estabelece na promoção dos bens sociais e dos direitos sociais (JAEGGI, 2009, p.528). Duas conclusões dessa assertiva: a primeira, que a instituição social possui um telos para a vida boa, ou seja, que a promoção (Beförderung) para a vida boa é a plenificação radical na práxis de uma instituição social. A própria Jaeggi assim salienta quando parafraseou Honneth ao afirmar que aquilo que pertence a uma instituição diz respeito a "indicar as condições supra-individuais para a autorrealização (autoefetividade) individual" (JAEGGI, 2009, p.528). Essa primeira questão ainda se orienta pela ideia central de que uma instituição não é apenas uma instância mediadora de nossos projetos privados ou públicos no tocante precisamente a bens sociais e direitos sociais. Isso reforça, para Jaeggi, a tese de que o uso de um fundamento social-ontológico pautado numa concepção crítica de filosofia social diz respeito a três aspectos: nocional (o que é uma instituição), funcional e efetivo (como uma instituição realiza sua(s) tarefa(s) na soci-

ASSAI, José Henrique Sousa. A questão do argumento social-ontológico na filosofia social: a instituição social como fonte de pesquisa crítico-normativa. Griot : Revista de Filosofia, Amargosa, Bahia, v.16, n.2, p.205-220, dezembro/2017. 
edade) (JAEGGI, 2009, p.528). De forma reiterada no quadro explicitativo dessa pesquisa mais uma vez a tarefa de uma forma destranscendental da razão se coloca enquanto esteio para uma filosofia social calcada em base social-ontológica já que a esfera efetiva de uma instituição (wie Institutionen wirken) (JAEGGI, 2009, p.529) é expressão de um corolário remissivo pertencente a uma concepção racional que "se incorpora" nos múltiplos contextos sociais e vitais. Daí o seu caráter destranscendental não só da razão, mas, sobretudo, da pesquisa crítica na filosofia social.

A segunda questão assinalada e que ainda remete à assertiva de Jaeggi acerca do imbricamento entre instituição e ontologia social é a ideia de "vida boa". Parece que o conceito de "vida boa" (guten Lebens) é o modus operandi que Jaeggi utiliza para não admitir, sob o crivo destranscendental da razão, uma posição metafísica e nem um realismo radical, pois quando Jaeggi descreve que as instituições tratam também de serem instâncias de mediação (Mittlerinstanzen) e instâncias de atribuição (Zuteilunginstanzen) de Bens e Direitos sociais (sozialen Gütern und Rechten) ela o faz tomando por contraponto três aspectos referentes à vida humana (subjetividade e coletividade): o processo de morte (Entlebendigung); do esvaziamento (Entleerung) e da erosão (Erosion) (JAEGGI, 2009, p.539). Uma situação que produz morte - violência, terrorismo, guerra, fome estrutural, má distribuição de renda, injustiça social etc. - é o que justamente uma instituição, sob a perspectiva crítica, deve combater enquanto tarefa imanente. Tal como ocorre no processo de morte nas instituições sociais em virtude da perca da capacidade de responder a ação deletéria de tal natureza assim também ocorre com o esvaziamento e a erosão nas instituições sociais. Tais termos são sinônimos do processo disruptivo de emancipação das instituições sociais. Como referencial prático ao combate desses três processos (Entlebendigung, Entleerung und Erosion) - sob uma perspectiva filosófica-social - temos o Programa Social Mais IDH do Governo do Estado do Maranhão (MARANHÃO, 2015, 113p). Quero explicitar brevemente a importância desse Programa Social como base explicitativa de minha argumentação e após essa brevíssima incursão eu retomarei as proposições de Jaeggi no tocante à força normativa das instituições sociais.

A despeito do cenário político institucional e a Operação Lava-Jato que também chegou ao Maranhão creio que a tarefa das instituições sociais nos munícipios mais pobres e com precariedade na assistência social e pública retrata a potência emancipatória dos munícipes em se organizarem em associações públicas e fazerem valer suas reivindicações normativas com vista à práxis. No intuito de erradicar os baixíssimos índices do IDHM (Índice de Desenvolvimento Municipal) - com as variantes "educação, saúde e renda" - o Mais IDH prevê

[...] como objetivo principal promover a superação da extrema pobreza e das desigualdades sociais no ambiente urbano e rural, por meio de estratégias de desenvolvimento territorial sustentável.

As diretrizes do Plano de Ações Mais IDH compreendem:

I - integração de políticas públicas com base no planejamento territorial;

II - ampliação dos mecanismos de participação popular na gestão das políticas públicas de interesse do desenvolvimento dos municípios;

III - ampliação da oferta dos programas básicos de cidadania;

IV - inclusão e integração produtiva das populações pobres e dos segmentos sociais mais vulneráveis, tais como trabalhadores rurais, quilombolas,

ASSAI, José Henrique Sousa. A questão do argumento social-ontológico na filosofia social: a instituição social como fonte de pesquisa crítico-normativa. Griot : Revista de Filosofia, Amargosa, Bahia, v.16, n.2, p.205-220, dezembro/2017. 
indígenas e populações tradicionais, calcado em um modelo de desenvolvimento que atenda às especificidades de cada um deles;

V - valorização da diversidade social, cultural, econômica, política, institucional e ambiental das regiões e das populações.

As ações do Plano deverão ser executadas de forma descentralizada e integrada, por meio da conjugação de esforços entre o Estado e os municípios, observadas a intersetorialidade, a transdisciplinaridade, a integralidade, a participação da sociedade civil e o controle social (MARANHÃO, 2015, p.8)

Através do Decreto $\mathrm{N}^{\circ} 30.612$ de 02 de janeiro de 2015 o programa social "Mais IDH" preconiza não só a importância da sociedade civil (dos munícipes) na construção de uma sociedade melhor, mas também a exigência da organização institucional para efeito de mediação normativa. A partir do governo assumido por Flávio Dino revigorou-se a tarefa da iniciativa popular mediante a ereção de instituições sociais para pelo menos minimizar os impactos deletérios de gestões já cinquentenárias nesse Estado federativo.

Na tentativa de resolver as patologias no (do) mundo da vida, o processo de consolidação (Verfestigung) e promoção (Beförderung) no mundo da vida social (efetivação de bens e direitos sociais) de tantos munícipes se efetiva mediante dois mecanismos procedimentais: o diagnóstico preliminar cuja prioridade é a realidade local no tocante aos três eixos do "Mais IDH" (educação, saúde e renda); o segundo é o diagnóstico avançado no qual colherá as informações dos trinta municípios envolvidos no programa do executivo maranhense (a escolha é pelos índices que dizem respeito aos três eixos do "Mais IDH"). Assim, "além do existente e consolidado, tendências futuras deverão ser identificadas a partir da realização/previsão de investimentos de grande porte, sejam públicos ou privados" (MARANHÃO, 2015, p.10).

Quanto à questão da normatividade creio que esses dois momentos (diagnóstico preliminar e diagnóstico avançado) em seus pressupostos preenchem os requisitos de uma proposta normativa e no que diz respeito ao diagnóstico avançado a presença textual "dos novos interlocutores no processo" enseja a participação pública e dos agentes sociais daquelas regiões. A participação não está centrada nos órgãos federais, porém desloca-se e também reside na atuação dos atores sociais ainda mais nesses casos onde peremptoriamente residem nessas regiões comunidades indígenas e quilombolas. Convém assinalar que a etapa do diagnóstico preliminar possui uma característica fundamental: "trata-se de uma ação inserida no marco do planejamento das políticas públicas estaduais, cujo ciclo completo parte da elaboração do planejamento plurianual - PPA e se desdobra na construção da lei de diretrizes orçamentárias - LDO e no da lei do orçamento anual - LOA" (MARANHÃO, 2015, p.6). Na arquitetônica orçamentária do Brasil fundamentada na Constituição Federal de 1988 no seu artigo 165 prevê que o orçamento público provém dessas três leis (PPA, LDO, LOA). Mesmo com as alterações sofridas na LOA e LDO com a Lei de Responsabilidade Fiscal o que "está em jogo" aqui é o espírito propositivo e normativo da ação pública e mais ainda das instituições sociais envolvidas no decurso do processo. $O$ "Mais IDH" resguarda o "espírito objetivo" de uma proposta pública de ação social mediante os canais das instituições participativas permitindo com que as patologias no mundo da vida daqueles munícipes alcancem um patamar de provisão ou assistência na resolução dos problemas. Aqui não se trata de uma questão ideológico-

ASSAI, José Henrique Sousa. A questão do argumento social-ontológico na filosofia social: a instituição social como fonte de pesquisa crítico-normativa. Griot : Revista de Filosofia, Amargosa, Bahia, v.16, n.2, p.205-220, dezembro/2017. 
partidária, porém com relação àquilo que concerne a uma filosofia social creio que o "Mais IDH" preencha minimamente os requisitos formais (não me coloco aqui na discussão do modus operandi desse referido programa) - portanto, os pressupostos (Grundannahme) de um pensar social - de uma proposta crítico-normativa de ação. A fundamentação aqui não fica alojada numa filosofia das ciências sociais como se poderia pensar, porém há um cerne da filosofia social no momento em que o que está em discussão não é apenas o modus operandi de uma determinada instituição, mas, de forma particular, a sua eficácia; ou seja, como uma instituição se efetiva (wie Institutionen wirken) na urdidura social.

A abordagem perquiridora da efetividade de uma instituição na qual Jaeggi se propôs a fazer em "Sozialphilosophie und Kritik" demarca o horizonte de entendimento e pesquisa da abordagem filosófica social ainda mais precisamente no tocante sobre a questão dos Bens sociais e Direitos sociais que também se vinculam com a ideia dos bens fundamentais (Grund güter) e dos bens públicos (Öffentliche Güter) (BRUNKHORST, 2002, 246p.) dos quais Brunkhorst se fundamenta. Dessa forma, a conquista da práxis social se traduz por meio do cânone de uma configuração normativa do Direito de existência social (soziale Existenzrecht) (BRUNKHORST, 2002, p.114).

E como o processo de consolidação da instituição social se efetiva? Para Jaeggi existem dois aspectos (JAEGGI, 2009, p.533 - 534): o primeiro trata do caráter genésico institutivo, ou seja, a instituição social não se define enquanto uma forma natural desprovida de normas/regras; ao contrário, ela é erigida (eingerichtet), ou seja, ela emerge mediante ações espontâneas dos sujeitos; quanto ao segundo, diz respeito à delimitação no sentido de que as instituições enquanto práticas sociais possuem característica "codificadora"; isto é, elas traduzem, sob o ponto de vista jurídico, o ordenamento social. Apesar de nessa passagem do texto a Rahel Jaeggi se aproxima de Searle e Maurice Hauriou não citando Habermas, eu penso que entender o Direito enquanto medium normativo do tecido social - ainda que no bojo da teoria social habermasiana seja fundamentada pela ação comunicativa e não por um pensar institucional-normativo - não deveríamos, ainda assim, olvidar as investigações habermasianas a esse respeito (HABERMAS, 1994, 704p; HABERMAS, 1997, 354p, v.2).

Sobre a questão acerca da consolidação (Verfestigung) da instituição social é bom assinalar que, para Jaeggi, nosso mundo social é tecido por uma matéria-prima chamada de instituição, porém a fim de que ela se consolide no mundo social é necessário observar que o aparato social cria tanto uma estrutura regulamentadanormativa e ética; e, por outro lado, a instituição tem a tarefa de estabilizar o mundo social (JAEGGI, 2009, p. 535 - 536). A estabilidade, por sua vez, produz imputabilidade (Zurechenbarkeit) - ou também na tradução inglesa "accountability" - e a supra-personalidade (Überpersönliche) no sentido de que cada instituição tem em si mesma um critério de autorreferencialidade (para todos os envolvidos) e outro critério que pressupõe um "eu" que se maximiza no agir coletivo.

Se para Jaeggi a consolidação da instituição social é um dado importante e fundamental em sua obra "Sozialphilosophie und Kritik" cuja coautoria em seu capítulo "Was ist eine (gute) Institution?" lhe rendeu créditos suficientes para que se tome a sério o argumento social-ontológico na pesquisa crítica, para Titus Stahl a questão é, prima facie, mais formal (STAHL, 2013, 475 p.). À pergunta sobre uma

ASSAI, José Henrique Sousa. A questão do argumento social-ontológico na filosofia social: a instituição social como fonte de pesquisa crítico-normativa. Griot : Revista de Filosofia, Amargosa, Bahia, v.16, n.2, p.205-220, dezembro/2017. 
justificação social-ontológica para uma proposta crítica de pensamento pressupôs literalmente a inquirição "em que sentido existe na realidade social os potenciais normativos que devem ser tomados por uma crítica da sociedade?" E mais ainda: "Sobre a existência (Existenz) das normas imanentes (immanenter Normen) quais premissas devemos aceitar para justificar afirmações sobre o conteúdo de (as) normas imanentes?" (STAHL, 2013, p.191). Tal pergunta incorre, para Stahl, que as expressões que se referem a conteúdos normativos são, antes de tudo, expressões sócioontológicas (sozialontologische Aussagen), pois elas pressupõem entidades sociais. Sobre o ponto de vista do argumento social-ontológico nem Jaeggi e nem tampouco Honneth tematizaram a esse respeito; por outro lado, Stahl despendeu três grandes partes da "Immanente Kritik: Elemente einer Theorie sozialer Praktiken" (IK) para dar conta de tais questões que, em última instância, se funde em uma grande questão que se faz decisiva na perspectiva da fundamentação de uma filosofia social no tocante ao binômio "ontologia social e instituição social" (justifica-se a existência de normas imanentes na urdidura social?): a primeira parte "Von der immanenten Kritik zur Sozialontologie" parte do conceito mais fundamental de crítica (que pressupõe os conceitos de crítica interna e externa e crítica reconstrutiva) social permeando pela hermenêutica até chegar aos modelos de racionalidade (comunicativo e reconhecimento); a segunda trata sobre "Die sozialontologische Voraussetzungen immanenter Kritik" e nessa parte ele trata sobre a intencionalidade coletiva e também as normas imanentes da práxis social; por fim, o tema da "Von der Sozialontologie zur immanenten Kritik" versa sobre a possibilidade de uma crítica imanente que centra sua reflexão na ambivalência entre normas sociais e conflitos sociais cotejando a crítica imanente com a epistemologia até concluir com uma "Verdinglichungkritik".

Uma vez que Stahl parte do princípio de que as práticas sociais são entendidas como "conexões interativas reguladas normativamente" (STAHL, 2013, p.15) e a normatividade enquanto potencialidade é encontrada na própria prática social dos grupos sociais e demais associações (o que pressupõe a ideia de entidade social) ele afirma que no entrecruzamento "premissas sociais-ontológicas e entidades sociais" dois modelos argumentativos são dispostos: atitudes normativas compartilhadas (Geteilte normative Haltungen) e o conteúdo normativo das práticas sociais (Der normative Gehalt sozialer Praktiken). Essa dual articulação fundamenta minha assertiva acerca da abordagem ontológica-social como possibilidade normativa de ação principalmente porque o próprio Stahl afirma em $I K$ que o primeiro modelo argumentativo (geteilter kollektiver Haltungen) não é suficiente para fundamentar uma crítica imanente porque, primeiro, não se tematiza nesse ponto o uso linguístico bem como das convicções e valores compartilhados e, em segundo, careceria de maior explicitação as condições intencionais da ideia sobre a institucionalização na sociedade na qual se baseia o primeiro argumento. Disso decorre que haveria necessidade de completar a análise das atitudes coletivas com a questão das normas compartilhadas e isso tudo para tentar responder à questão da disponibilidade das normas práticas. Estou convencido a aceitar a ideia de que o conteúdo normativo das práticas sociais - principalmente nas instituições sociais - pode ser encontrado "nas" mesmas práticas sociais o que acarretaria afirmar que uma instituição social - mais precisamente

ASSAI, José Henrique Sousa. A questão do argumento social-ontológico na filosofia social: a instituição social como fonte de pesquisa crítico-normativa. Griot : Revista de Filosofia, Amargosa, Bahia, v.16, n.2, p.205-220, dezembro/2017. 
no quadro referencial de uma instituição participativa (IP $)^{3}$ - possui em seu escopo um conjunto de conteúdos normativos ancorados nas práticas sociais dessa mesma IP. Dessa forma, creio que numa IP ancorada em uma teoria crítica da sociedade (Gesellschaftskritik) (STAHL, 2013, p.30 - 34) nos forneceria condições de se pensar uma possibilidade normativa de emancipação das patologias no mundo da vida.

Titus Stahl parte do entendimento de que uma "Gesellschaftskritik" possui dois sentidos: sentido ampliado (im weiten Sinne) diz respeito à busca pelo melhoramento das práticas sociais e das instituições sociais só que nesse caso os participantes do (no) processo de aperfeiçoamento de tais práticas e das instituições os participantes ainda não possuem um vínculo formal que lhes garanta e justifique suas pretensões normativas em conjunto. No sentido estrito (im engeren Sinne) o apelo ou a reivindicação fundamentada para a modificação da realidade social reside numa forma paradigmática. Aqui as pretensões normativas indicam como os participantes ou endereçados no processo social devem proceder. Nesse caso, as práticas sociais devem ser tematizadas assim como as intenções práticas devem ser medidas (mensuradas) em seus padrões avaliativos e de normas para que dessa forma todas as convicções das ações sejam justificadas no intuito do melhoramento das práticas sociais.

Por fim, em $I K$ a constituição sócio-ontológica das práticas sociais ainda se encontra ancorada na tradição searleana, porém mesmo atendendo satisfatoriamente ao conceito de ontologia social (SEARLE, 2006, p.51 - 71) não creio que o faça da mesma forma ao vincular uma forma argumentativa ontológica-social às formas institucionais normativas (com telos à práxis); mas, contrariamente, principalmente as contribuições de Jaeggi se orientam na tratativa em vincular para a pesquisa crítica um argumento social-ontológico. Daí o caráter compreensivo e reflexivo da filosofia social em conceber, em última instância, uma instituição social enquanto forma de vida ética (FORST, 2015, 254p) que, sob o ponto de vista de uma concepção racional destranscendental, se remete aos ordenamentos normativos da (na) sociedade (FORST, 2015, p.87). Ordenamentos esses que estão profundamente enraizados numa concepção política-democrática onde a instituição social se torna sua variante compreensiva. No entanto, ainda persiste o repto da filosofia social na edificação de um pensamento e de uma práxis emancipatórias cuja orientação se fundamente na efetivação da ordem social no interior de uma ordem democrática. Essa efetividade social (bens e direitos sociais) continua a se estabelecer como elemento heurístico e não-terminativo na pesquisa crítica.

\footnotetext{
${ }^{3}$ III ENCONTRO INTERNACIONAL PARTICIPAÇÃO, DEMOCRACIA E POLÍTICAS PÚBLICAS, 2017, Vitória (ES). Seminário Temático Efetividade das instituições participativas, 2017.
}

ASSAI, José Henrique Sousa. A questão do argumento social-ontológico na filosofia social: a instituição social como fonte de pesquisa crítico-normativa. Griot : Revista de Filosofia, Amargosa, Bahia, v.16, n.2, p.205-220, dezembro/2017. 


\section{Referências bibliográficas}

ASSAI, José Henrique Sousa. De "Leiden an Unbestimmtheit" à "Erfolg an Bestimmtheit": um caminho possivel da reconstrução normativa honnethiana?, Griot, Amargosa (Bahia), v. 11, n.1, p. $226-244.2015$.

- A Fundamentação discursiva da teoria política em Jürgen Habermas: uma abordagem empírico-normativa do Estado. Imperatriz: Ética, 2008. 180 p.

AUDARD, Catherine. Cidadania e Democracia Deliberativa. Tradução Walter Valdevino. Porto Alegre: EDIPUCRS. 2006, 156 p. (Coleção Filosofia 199).

BAYERTZ, Kurt. Solidarity. London: Kluwer Academic Publishers, 1999. 350 p.

BODE, Ingo. Die Organisation der Solidarität: Normative Interessenorganisationen der französischen Linken als Auslaufmodell mit Zukunft. Opladen: Westdeutscher Verlag, 1997. 366 p.

BRUNKHORST, Hauke. Solidarität: Von der Bürgerfreundschaft zur globalen Rechtsgenossenschaft. 1. ed. Frankfurt am Main: Suhrkamp Verlag, 2002. 246 p.

FORST, Rainer et.al. (org). Sozialphilosophie und Kritik. 1. ed. Frankfurt am Main: Suhrkamp Verlag, 2009. 743p.

FORST, Rainer. Normativität und Macht: Zur Analyse sozialer Rechtfertigungsordnungen. 1. ed. Berlin: Suhrkamp Verlag, 2015. 254 p.

- Kontexte der Gerechtigkeit: politische Philosophie von Liberalismus und Kommunitarismus. 1. ed. Frankfurt am Main: Surhkamp, 1996. 480p.

HABERMAS, Jürgen. Entre Naturalismo e Religião: Estudos Filosóficos. Tradução Flávio Beno Siebeneichler. Rio de Janeiro: Tempo Brasileiro, 2007. p. 19.

Kommunikatives Handeln und detranszendentalisierte Vernunft. Stuttgart:

Reclam, 2001. 87 p.

Direito e Democracia: entre facticidade e validade. Tradução Flávio Beno Sie-

beneichler. Rio de Janeiro: Tempo Brasileiro, 1997. 354 p. v. 2.

- Faktizität und Geltung: Beiträge zur Diskurstheorie des Rechts und des demokratischen Rechtsstaats. 4 ed. Frankfurt am Main: Suhrkamp Verlag, 1994. 704 p.

HONNETH, Axel. Die Idee des Sozialismus: Versuch einer Aktualisierung. Berlin: Suhrkamp Verlag, 2015. 167p.

. Freedom's Right: The Social Foundations of Democratic Life. Tradução Joseph Ganahl. Cambridge: Polity Press, 2014. 411 p.

Pathologien der Vernunft: Geschichte und Gegenwart der Kritischen Theorie.

Frankfurt am Main: Suhrkamp Verlag, 2007. 239 p.

- Sofrimento de Indeterminação: uma reatualização da Filosofia do direito de

Hegel. Tradução Rúrion Soares Melo. São Paulo: Esfera Pública, 2007. 145 p.

. Luta por reconhecimento: a gramática moral dos conflitos sociais. Tradução

Luiz Repa. São Paulo: Ed. 34, 2003. 296 p

Leiden an Unbestimmtheit: Eine Reaktualisierung der Hegelschen

Rechtsphilosophie. Stuttgart: Reclam, 2001. 127 p.

The Fragmented World of the Social: Essays in Social and Political Philosophy. New York: State University New York Press, 1995. 343p.

. Die nachholende Revolution: Kleine Politische Schriften VII. Frankfurt am Main: Suhrkamp Verlag, 1990. 223p.

ASSAI, José Henrique Sousa. A questão do argumento social-ontológico na filosofia social: a instituição social como fonte de pesquisa crítico-normativa. Griot : Revista de Filosofia, Amargosa, Bahia, v.16, n.2, p.205-220, dezembro/2017. 
HONNETH, Axel, HERZOG, Lisa (org.). Der Wert des Marktes: Ein ökonomischphilosophischer Diskurs vom 18. Jahrhundert bis zur Gegenwart. Berlin: Suhrkamp Verlag, 2014.670p.

III ENCONTRO INTERNACIONAL PARTICIPAÇÃO, DEMOCRACIA E POLÍTICAS PÚBLICAS, 2017, Vitória (ES). Seminário Temático Efetividade das instituições participativas, 2017.

JAEGGI, Rahel. Kritik von Lebensformen. 1 ed. Berlin: Suhrkamp Verlag, 2014a. $451 p$.

JAEGGI, Rahel. Alienation. Tradução Frederick Neuhouser e Alan E. Smith. New York: Columbia Press, 2014b. 274p.

Karl Marx: Perspektiven der Gesellschaftskritik. New York: De Gruyter, 2013. 307p.

JAEGGI, Rahel, LOICK, Daniel (org.). Nach Marx: Philosophie, Kritik, Praxis. 2. ed. Berlin: Suhrkamp Verlag, 2014. 518p.

LUBENOW, Jorge Adriano. O que há de político na Teoria da Ação Comunicativa? Sobre o déficit de institucionalização em Jürgen Habermas. Philósophos, Goiânia, v.18, n.1, p.157 - 190, 2013a.

LUBENOW, Jorge Adriano. Hauke Brunkhorst e o conceito de solidariedade democrática como crítica à esfera pública pós-nacional de Jürgen Habermas. Veritas, Porto Alegre, v. 58, n. 1, p.118-130, 2013b.

LIMA, Francisco Jozivan. Hiperinflação literária e déficit sócio-normativo no Das Recht der Freiheit de Honneth. 2014. 21f. Trabalho apresentado como requisito parcial para aprovação na disciplina Seminário de Filosofia Social (Doutorado em Filosofia), PUCRS, Porto Alegre, 2014.

MARANHÃO (Estado). Secretaria de Estado do Planejamento e Orçamento. Instituto Maranhense de Estudos Socioeconômicos e Cartográficos. Plano de Ação Mais IDH. São Luís, 2015. 113 p.

NETO, Nilo. Orçamento Participativo: o processo de implementação em São Luís. 2009. 156f (Dissertação). Mestrado em Políticas Públicas. Universidade Federal do Maranhão, São Luís, 2009.

OLIVEIRA, Nythamar de. Tractatus Politico-Theologicus: Teoria Crítica, Libertação e Justiça. Porto Alegre: Editora Fi, 2016. 271 p.

SEARLE, John. Social Ontology: Some Basic Principles. [S.L.:s.n], 2006. p. $51-71$.

SOBOTTKA, Emil. A liberdade individual e suas expressões institucionais. Revista Brasileira de Ciências Sociais, v. 27, n. 80, p.219 - 227.

Orçamento Participativo: conciliando direitos sociais de cidadania e legitimidade do governo. Civitas: Revista de Ciências Sociais, Porto Alegre, v. 4, n. 1, p. 95 $109,2004$.

SOBOTTKA, Emil, SAVEDRA, Giovani. Introdução à teoria do reconhecimento de Axel Honneth. Civitas: Revista de Ciências Sociais, Porto Alegre, v. 8, n. 1, p. 9 - 18 , 2008.

STAHL, Titus. Immanente Kritik: Elemente einer Theorie sozialer Praktiken. Frankfurt am Main: Campus Verlag, 2013. 475p.

Autor(a) para correspondência: José Henrique Sousa Assai, Universidade Federal do Maranhão, Av. dos Portugueses, 1966, Vila Bacanga, CEP 65080-805, São Luís - MA, Brasil. jhsassai@ufma.br

ASSAI, José Henrique Sousa. A questão do argumento social-ontológico na filosofia social: a instituição social como fonte de pesquisa crítico-normativa. Griot : Revista de Filosofia, Amargosa, Bahia, v.16, n.2, p.205-220, dezembro/2017. 